Check for updates

Cite this: Phys. Chem. Chem. Phys., 2020, 22, 5604

Received 4th December 2019, Accepted 31st January 2020

DOI: $10.1039 / \mathrm{c} 9 \mathrm{cp} 06568 \mathrm{~g}$

rsc.li/pccp

\title{
Vibrational dynamics in lead halide hybrid perovskites investigated by Raman spectroscopy $\dagger$
}

\author{
Josefa Ibaceta-Jaña, (D) a Ruslan Muydinov, ${ }^{* a}$ Pamela Rosado, ${ }^{b}$ \\ Hossein Mirhosseini, (D c Manjusha Chugh, ${ }^{c}$ Olga Nazarenko, de Dmitry N. Dirin, (iD de \\ Dirk Heinrich, ${ }^{b}$ Markus R. Wagner, ID b Thomas D. Kühne, ${ }^{c}$ Bernd Szyszka, (D) ${ }^{\text {a }}$ \\ Maksym V. Kovalenko iD de and Axel Hoffmann ${ }^{b}$
}

\begin{abstract}
Lead halide perovskite semiconductors providing record efficiencies of solar cells have usually mixed compositions doped in A- and X-sites to enhance the phase stability. The cubic form of formamidinium (FA) lead iodide reveals excellent opto-electronic properties but transforms at room temperature (RT) into a hexagonal structure which does not effectively absorb visible light. This metastable form and the mechanism of its stabilization by $\mathrm{Cs}^{+}$and $\mathrm{Br}^{-}$incorporation are poorly characterized and insufficiently understood. We report here the vibrational properties of cubic FAPbl 3 investigated by DFT calculations on phonon frequencies and intensities, and micro-Raman spectroscopy. The effects of $\mathrm{Cs}^{+}$and $\mathrm{Br}^{-}$ partial substitution are discussed. We support our results with the study of $\mathrm{FAPbBr}_{3}$ which expands the identification of vibrational modes to the previously unpublished low frequency region $\left(<500 \mathrm{~cm}^{-1}\right)$. Our results show that the incorporation of $\mathrm{Cs}^{+}$and $\mathrm{Br}^{-}$leads to the coupling of the displacement of the A-site components and weakens the bonds between $\mathrm{FA}^{+}$and the $\mathrm{PbX}_{6}$ octahedra. We suggest that the enhancement of $\alpha-\mathrm{FAPb}_{3}$ stability can be a product of the release of tensile stresses in the $\mathrm{Pb}-\mathrm{X}$ bond, which is reflected in a red-shift of the low frequency region of the Raman spectrum $\left(<200 \mathrm{~cm}^{-1}\right)$.
\end{abstract}

\section{Introduction}

Lead halide perovskites (LHPs $=\mathrm{A}[\mathrm{Pb}] \mathrm{X}_{3}$ ) have attracted the curiosity of researchers owing to their outstanding optoelectronic properties such as a sharp absorption edge, high absorption coefficients, the large diffusion length of free charge carriers, and low recombination rates. ${ }^{1,2}$ Furthermore, the band gap tunability, ${ }^{3-7}$ the small difference between the band gap size and the open circuit voltage, ${ }^{8}$ easy processing, and the high defect tolerance ${ }^{9,10}$ of LHPs make these compounds suitable for a variety of applications including light emitting devices, ${ }^{11}$ solar cells, ${ }^{3,12,13}$ phototransistors, ${ }^{14,15}$ lasers, ${ }^{16,17}$ and detectors. ${ }^{18-21}$ Among various LHPs, formamidinium $\left(\mathrm{CH}\left(\mathrm{NH}_{2}\right)_{2}{ }^{+}=\mathrm{FA}^{+}\right)$lead iodide $\left(\mathrm{FAPbI}_{3}\right)$ is

\footnotetext{
${ }^{a}$ Technology for Thin-Film Devices, Technische Universitat Berlin, Einsteinufer 25, 10587 Berlin, Germany. E-mail: ruslan.muydinov@tu-berlin.de

${ }^{b}$ Institute of Solid State Physics, Technische Universitat Berlin, Hardenbergstr. 36, 10623 Berlin, Germany

${ }^{c}$ Dynamics of Condensed Matter and Center for Sustainable Systems Design, Department of Chemistry, University of Paderborn, Warburger Str. 100, D-33098 Paderborn, Germany

${ }^{d}$ Institute of Inorganic Chemistry, Department of Chemistry and Applied Biosciences, ETH Zürich, Vladimir-Prelog-Weg 1-5/10, 8093 Zürich, Switzerland

${ }^{e}$ Laboratory for Thin Films and Photovoltaics, Empa-Swiss Federal Laboratories for Materials Science and Technology, Überlandstrasse 129, CH-8600 Dübendorf, Switzerland

$\dagger$ Electronic supplementary information (ESI) available. See DOI: 10.1039/c9cp06568g
}

of particular interest for solar cell applications due to its narrow band gap of around $1.55 \mathrm{eV}$, its improved thermal stability compared to that of methylammonium $\left(\mathrm{CH}_{3} \mathrm{NH}_{3}{ }^{+}=\mathrm{MA}^{+}\right)$lead iodide $\left(\mathrm{MAPbI}_{3}\right)$ and the easier solution processability compared to $\mathrm{CsPbI}_{3}{ }^{22-25}$ The main challenge for this material is the structural instability: at room temperature (RT) it transforms into the nonphotoactive yellow $\delta$-phase in 1 to 10 days depending on the environment. $^{25,26} \mathrm{~A}$ common way to circumvent this is to combine different cations on the A-site or halides on the X-site featuring quinary $\mathrm{Cs}_{x} \mathrm{FA}_{1-x} \mathrm{~Pb}\left(\mathrm{I}_{1-y} \mathrm{Br}_{y}\right)_{3}$ composition with $x$ and $y$ about $10 \%$ each. This strategy has been shown to improve the phase stability in bulk, microcrystalline and nanocrystalline forms. In solar cells, this is translated into improved photo and moisture stability under environmental conditions and reduction of trap density, which consequently increases the efficiency by more than $1 \% .^{3,12,20,27-29}$

Even though impressive progress in synthesis and device engineering has been made, some fundamental properties of LHPs remain poorly investigated. Particularly, the understanding of the lattice dynamics of LHPs is crucial for the further optimization of their performance due to the unusually high softness of LHPs compared to conventional semiconductors ${ }^{30-32}$ and the additional dynamic effects caused by the non-spherical geometry of organic A-cations. Their dipole moments in combination with the X-ion migration ${ }^{33}$ and the reorientation of A-cations within the $\mathrm{BX}_{6}$ octahedral frame ${ }^{34}$ result in a structural phase transition. ${ }^{35}$ 
Raman spectroscopy has already disclosed the lattice dynamics for some LHPs. The experimental Raman spectra of LHPs have been supported with Density Functional Theory (DFT) calculations only for $\mathrm{MAPbX}_{3}(\mathrm{X}=\mathrm{I}$ and $\mathrm{Br})$. The interesting range of the vibrational spectrum of these materials is $10-3100 \mathrm{~cm}^{-1}$ where the most pronounced peaks are correlated with the motion of the $\mathrm{PbX}_{6}$ octahedra and the reorientation of the $\mathrm{MA}^{+}$cation. These peaks appear in the spectra below and above $200 \mathrm{~cm}^{-1}$, respectively. ${ }^{36-39}$ Dynamic disorder of $\mathrm{MA}^{+}$causes splittings of independent harmonic modes, resulting in a larger number of Raman peaks at high frequencies. ${ }^{37}$ The variation of halogens in $\mathrm{MAPbX}_{3}$ shifts the Raman peaks in accordance to the $\mathrm{Pb}-\mathrm{X}$ bond strength. ${ }^{38,39}$ There are experimentally measured Raman spectra of $\mathrm{FAPbBr}_{3}$ and $\mathrm{CsPbBr}_{3}$ up to $3500 \mathrm{~cm}^{-1}$ and $320 \mathrm{~cm}^{-1}$, respectively, but the specific modes have not been ascribed for the whole spectrum. ${ }^{36,40-42}$ For $\mathrm{FAPbBr}_{3}$, the attribution is well-made for molecular modes $\left(>500 \mathrm{~cm}^{-1}\right)$, associating them with the Raman modes of the isolated $\mathrm{FA}^{+}$molecular ion. ${ }^{43}$ For $\mathrm{CsPbBr}_{3}$, a general description of modes was done on the basis of atomic trajectories, which reveals that $\mathrm{Cs}^{+}$atoms perform a head-to-head motion, which is the displacement of two neighboring $\mathrm{Cs}^{+}$atoms towards the same face, along the $\langle 100\rangle$ directions. Comparative studies of $\mathrm{MAPbX}_{3}$ and $\mathrm{CsPbX}_{3}$ demonstrated a number of correlating Raman peaks representing the analogous motions for both compounds. ${ }^{36,42}$ Despite the existence of molecular dynamics simulations performed for $\mathrm{FAPbI}_{3},{ }^{44,45}$ its vibrational behavior and internal dynamics have not been correlated with experimental data so far. Only one Raman peak at $110 \mathrm{~cm}^{-1}$ has been experimentally determined. ${ }^{25}$ There are also no experimental data for the mixed FA-based compounds at all. Therefore, the effect of $\mathrm{Cs}^{+}$and $\mathrm{Br}^{-}$ doping in the lattice dynamics also remains poorly understood.

In this work we investigate $\mathrm{FAPbI}_{3}$ and $\mathrm{FAPbBr}_{3}$ by means of Raman spectroscopy and identify the origin of the different vibrational modes with the support of DFT calculations. ${ }^{46}$ The measurements were conducted on single crystal perovskites which exhibit less defects compared to their polycrystalline counterparts. Solution based growth provides an even distribution of components and a good level of the process control. We intend to understand the impact of $\mathrm{Cs}^{+}$and $\mathrm{Br}^{-}$incorporation into $\mathrm{FAPbI}_{3}$ through the quantification of Raman modes and Raman shifts. A compositional cross-check is performed: single crystalline $\mathrm{FAPbI}_{3}$ and $\mathrm{FAPbBr}_{3}$ are compared to identify the sublattice $\mathrm{PbX}_{6}$ modes and $\mathrm{FA}^{+}$movements. Comparing $\mathrm{FAPbBr}_{3}$ with $\mathrm{CsPbBr}_{3}$ enables the identification of $\mathrm{Br}^{-}$related vibrational modes and to differentiate between $\mathrm{FA}^{+}$ and $\mathrm{Cs}^{+}$cations. A complex effect of the partial cation and anion substitutions is observed in relatively stable $\mathrm{Cs}_{0.1} \mathrm{FA}_{0.9} \mathrm{PbI}_{3}$ and $\mathrm{Cs}_{0.1} \mathrm{FA}_{0.9} \mathrm{PbI}_{2.6} \mathrm{Br}_{0.4}$ compositions. By analyzing the cooperative effects of the noticed substitutions we propose an explanation for the observed stabilization of the cubic structure at RT.

\section{Methods}

\section{Sample preparation}

Single crystalline samples of the compositions presented in Fig. 1 were prepared using the modified inverse temperature crystallization (ITC) method reported elsewhere. ${ }^{20,25,26,47}$
The $\gamma$-butyrolactone (GBL) based-solutions were prepared in ambient air ( $\mathrm{RT}=17{ }^{\circ} \mathrm{C}$ ) and next filtered through a $0.2 \mu \mathrm{m}$ polytetrafluoroethylene syringe filter. The filtered precursor solution of $3 \mathrm{ml}$ volume was poured into a $20 \mathrm{ml}$ vial, closed with a cap, and placed into a preheated $\left(90{ }^{\circ} \mathrm{C}\right)$ glycerol bath. The temperature was elevated in $5{ }^{\circ} \mathrm{C} \mathrm{h}^{-1}$ steps up to $130{ }^{\circ} \mathrm{C}$ maximum and kept for $3 \mathrm{~h}$. The crystals formed were wiped with a filter paper and dried under ambient conditions. To grow large enough crystals of the $\mathrm{Cs}_{0.1} \mathrm{FA}_{0.9} \mathrm{PbI}_{3}$ and $\mathrm{FAPbI}_{3}$ compositions, a previously obtained seed was introduced at $95{ }^{\circ} \mathrm{C}$ into the solution. Seeds were obtained using the method of Han et al. ${ }^{25}$ by keeping a not-filtered $1 \mathrm{M}$ precursor solution at $70{ }^{\circ} \mathrm{C}$ for 6 hours followed by their growth in a freshly prepared and filtered solution at $115{ }^{\circ} \mathrm{C}$ for $3 \mathrm{~h}$.

\section{Analytical methods}

Powder X-ray diffraction (XRD) patterns were collected in transmission (Debye-Scherrer-geometry) with a STADI P diffractometer (STOE \& Cie GmbH), equipped with a silicon strip MYTHEN $1 \mathrm{~K}$ Detector (DECTRIS) with a curved Ge(111)-Monochromator. For the measurement, single crystals were ground and placed between adhesive tapes.

Raman spectroscopy was performed on a high-resolution LabRAM HR800 spectrometer from Horiba. It included an ultra-low frequency (ULF) unit capable of measuring Raman spectra from $10 \mathrm{~cm}^{-1}$ at an excitation wavelength of $633 \mathrm{~nm}$. Spectra were recorded with gratings of 600 and 1800 lines per millimeter at RT in an ambient environment. The laser beam was focused using a $50 \times / \mathrm{NA}=0.75$ microscope objective, with a spot diameter of $1.03 \mu \mathrm{m}$ and a power intensity in the range from $6 \mu \mathrm{W}$ to $280 \mu \mathrm{W}$. This results in a power density in the range from $0.8 \mathrm{~kW} \mathrm{~cm} \mathrm{~cm}^{-2}$ to $35.6 \mathrm{~kW} \mathrm{~cm}^{-2}$.

We notice here that the acquisition and interpretation of Raman spectra are challenging in the case of the LHPs, due to the combination of two counteracting effects: (i) the low relative intensity of Raman scattering compared to the primary excitation power and (ii) the high rate of degradation of LHPs under laser induced heating. ${ }^{48}$ For a laser wavelength $\lambda=532 \mathrm{~nm}$, the LHPs are degraded at a beam power higher than $>10 \mu \mathrm{W}$. We detected degradation of FA-based LHPs at $>1 \mathrm{~mW}$ at an excitation wavelength $\lambda=633 \mathrm{~nm}$. Consequently, the excitation power and integration times were optimized for each LHP to ensure good signal to noise ratios while avoiding laser induced material degradation during the measurements. To avoid parasitic light signals, the measurements were performed in the dark. Due to the onset of strong luminescence in $\mathrm{FAPbI}_{3}$ (PL signal around $\lambda=827 \mathrm{~nm}$ ), the Raman spectrum of this compound is only shown

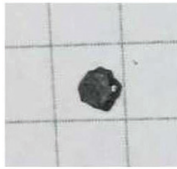

(a)

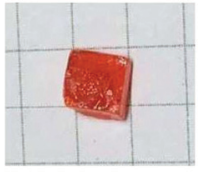

(b)

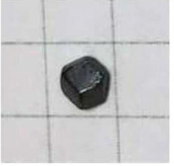

(c)

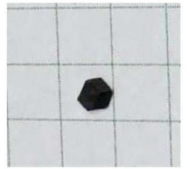

(d)
Fig. 1 Photographs of single crystals: (a) $\mathrm{FAPbl}_{3}$, (b) $\mathrm{FAPbBr}_{3}$, (c) $\mathrm{Cs}_{0.1} \mathrm{FA}_{0.9} \mathrm{Pbl}_{3}$ and (d) $\mathrm{Cs}_{0.1} \mathrm{FA}_{0.9} \mathrm{Pbl}_{2.6} \mathrm{Br}_{0.4}$. 
up to $200 \mathrm{~cm}^{-1}$. The same limitation applies for mixed compounds at frequencies above $1200 \mathrm{~cm}^{-1}$. For $\mathrm{CsPbBr}_{3}$, the spectra were found to be informative up to $400 \mathrm{~cm}^{-1}$. Despite the limitation in the measured range, the source at $\lambda=633 \mathrm{~nm}$ gives the sharpest peaks and lowest noise. A less energetic excitation source $(\lambda=830 \mathrm{~nm})$ also excites $\mathrm{FAPbI}_{3}$, emitting photoluminescence that reduces the possibility of identifiable peaks.

Expecting exclusively molecular $\left(\mathrm{FA}^{+}\right)$modes in Zone III, we considered the $\mathrm{FAPbBr}_{3}$ compound as a reference. Besides, among FA-based LHPs, only this compound is experimentally characterized by Raman spectroscopy in the literature. ${ }^{40}$

\section{Computational details}

DFT based total energy and force calculations were performed using the Vienna Ab initio Simulation Package (VASP) code. ${ }^{49}$ The projector augmented (PAW) potentials ${ }^{50,51}$ that describe electron-ion interactions were constructed such that the $5 \mathrm{~d}$ electrons of $\mathrm{Pb}, 4 \mathrm{~s}$ and $4 \mathrm{p}$ electrons of $\mathrm{Br}$, and $5 \mathrm{~s}$ and $5 \mathrm{p}$ electrons of I are treated as valence electrons. The plane-wave cutoff energy was set to $700 \mathrm{eV}$. A force convergence criterion of

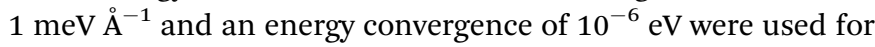
all geometry optimizations. A Gamma-centered MonkhorstPack set of $k$-points of $6 \times 6 \times 6$ was used for Brillouin zone integration. To take the weak van der Waals interactions into account, the optB88-vdW functional ${ }^{52}$ with default setting of the VASP was used. Cubic phases of $\mathrm{FAPbI}_{3}$ and $\mathrm{FAPbBr}_{3}$ perovskite compounds with experimentally measured lattice parameters (6.36 and 5.99 AA, respectively) were considered. Spin-polarized calculations for the primitive cells and $2 \times 2 \times 2$ cells showed no change in the atomic configuration, therefore, the rest of the calculations were performed on primitive cells. First-principles lattice dynamics (phonon spectrum) calculations were performed for the cubic phases of $\mathrm{FAPbI}_{3}$ and $\mathrm{FAPbBr}_{3}$ by diagonalizing the Hessian matrix within the Harmonic approximation. ${ }^{53}$ We used the finite difference method to calculate the force constants. The eigenvectors of the Hessian matrix give the normal modes of the vibrations of the atoms, whereas the eigenvalues represent their frequencies. After obtaining the normal modes, Raman intensities (activities) of these modes were obtained by calculating the change in polarizability (macroscopic dielectric tensor) of each normal mode. Diagonalization of the Hessian matrix gives imaginary frequencies if the structure is not well optimized. Hence, we first optimized the atomic structures with a rather tight convergence criterion as mentioned above.

\section{Results and discussion}

\section{Theoretical Raman spectra of $\mathrm{FAPbBr}_{3}$ and $\mathrm{FAPbI}_{3}$}

DFT calculations were performed to attribute the modes in the case of poorly investigated $\mathrm{FAPbBr}_{3}$ and $\mathrm{FAPbI}_{3}$. To validate our model, we performed DFT calculations for MAPbI $_{3}$ (see Fig. S1, ESI $\dagger$ ) and our results were found to be in good agreement with the data published previously. ${ }^{37}$ The calculated Raman spectra of $\mathrm{FAPbX}_{3}$ are shown in Fig. 2. The modes of the high frequency range (500-3500 $\mathrm{cm}^{-1}$ ) for some FA-based compounds were also explored experimentally ${ }^{40,43}$ and our DFT data agree well with the experimental data for $\mathrm{FAPbBr}_{3} \cdot{ }^{40}$

Raman spectra of hybrid perovskites are usually analyzed in three spectral ranges which correspond to different sources of vibrations. ${ }^{37}$ The low-energy range from 10 to $50 \mathrm{~cm}^{-1}$ (Zone I)

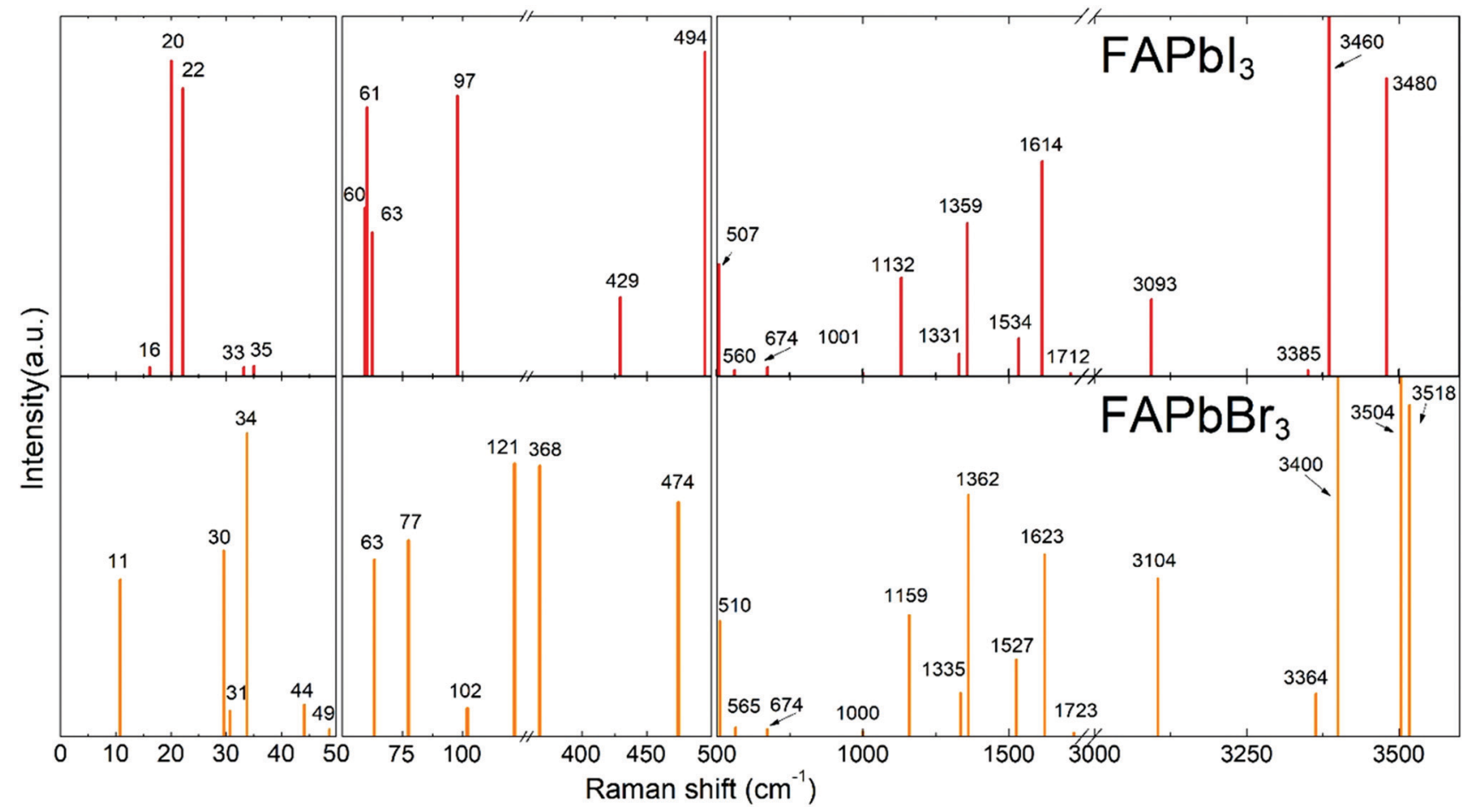

Fig. 2 DFT calculated Raman spectra of the cubic $\mathrm{FAPbl}_{3}$ and $\mathrm{FAPbBr}_{3}$ perovskites. 
contains $\mathrm{PbX}_{6}$ sublattice modes. Zone II, from 50 to $500 \mathrm{~cm}^{-1}$, corresponds to the coupled modes, which appear exclusively in LHPs. They present the $\mathrm{FAPbX}_{3}$ molecular reorientation of $\mathrm{FA}^{+}$ influenced by the $\mathrm{PbX}_{6}$ octahedral framework. Zone III, the high-energy zone from 500 to $3500 \mathrm{~cm}^{-1}$, includes individual molecular modes. It is worth noticing that all modes are affected by the coupling, however, this coupling is the source of the vibration only in Zone II. The modes of Zones I and III are present in isolated octahedra and isolated molecules, respectively.

The following results are structured in accordance with these three zones. We explain the modes of Zones I and III by comparison with theoretical modes from the literature. ${ }^{37,43}$ The modes of Zone II are extensively explained due to the absence of references in the literature.

In Zone I, our calculations show peaks related to the octahedral modes, which are twist and distortion vibrations characteristic for the $O_{\mathrm{h}}$ symmetry (see Fig. S2, ESI $\dagger$ ). For $\mathrm{FAPbI}_{3}$, the twist mode is present at 16,20 and $22 \mathrm{~cm}^{-1}$ and the distortion mode is present at 33 and $35 \mathrm{~cm}^{-1}$. For $\mathrm{FAPbBr}_{3}$, these modes are present at 30 and $31 \mathrm{~cm}^{-1}$ and at 34,44 and $63 \mathrm{~cm}^{-1}$, respectively.

A comparison between our calculated modes of Zone I with experimental Raman modes cannot be made due to the lack of Raman data of $\mathrm{FAPbX}_{3}$ compositions in the literature. We can directly compare FAPbX $_{3}$ with other hybrid LPHs, such as $\mathrm{MAPbI}_{3}$, considering that the molecular response does not affect the frequencies of the octahedral modes significantly. This is a consequence of the lower mass of the molecules compared to the inorganic frame $\left(\mathrm{FA}^{+}=46 \mathrm{u}\right.$. compared to $\mathrm{PbX}_{6}=1000 \mathrm{u}$.). The modes of $\mathrm{MAPbI}_{3}$ were thoroughly ascribed on the basis of DFT calculations ${ }^{37}$ and corroborated by experiments. ${ }^{37,38}$ According to these data the peak associated with the octahedral twist in iodide appears at energies below $30 \mathrm{~cm}^{-1}$, whereas the octahedral distortion peak appears between 30 and $50 \mathrm{~cm}^{-1}$. In bromide, these modes shift about $15 \mathrm{~cm}^{-1}$ to higher frequencies. This happens due to the higher strength of the $\mathrm{Pb}-\mathrm{Br}$ bond $(0.66$ in the Pauling scale) compared to $\mathrm{Pb}-\mathrm{I}$ ( 0.33 in the Pauling scale) as well as due to the smaller atomic mass of $\mathrm{Br}(79.9 \mathrm{u}$.) compared to I $(126.9$ u.). The latter impacts peak positions as $\omega=\sqrt{k / m}$, according to the harmonic oscillator model. ${ }^{54}$ This model is the solution of the Schrödinger equation that describes the atomic vibrations in a system. For a simple scheme, in a diatomic molecule the frequency of the vibration " $\omega$ " depends directly on " $m$ ", that represents the reduced mass, and " $k$ ", that represents the spring constant, which is related to the strength of the chemical bond between the involved atoms.

Modes in Zone II for $\mathrm{FAPbX}_{3}$ have not been described in the literature so far. For this zone, our calculations showed mainly six modes which are (a) in-plane rotation around the center of mass, (b) in-plane rotation around corner hydrogen, (c) out-ofplane rotation around the $\mathrm{N}-\mathrm{N}$ axis, (d) molecular translation, and (e) asymmetric and (f) symmetric out-of-plane bending of $\mathrm{H}_{2} \mathrm{~N}-\mathrm{C}-\mathrm{NH}_{2}$ (see Fig. 3). The 2D representation of the HP modes shown in the figure is a schematization of the $3 \mathrm{D}$ models of the vibrations given by DFT calculations, in which the displacements are represented by arrows. $\mathrm{FAPbI}_{3}$ reveals these modes at $60,61,63,97,429$, and $494 \mathrm{~cm}^{-1}$, whereas $\mathrm{FAPbBr}_{3}$ peaks (excluding mode b) appear at 11, 77, 102/121, 368 and $474 \mathrm{~cm}^{-1}$, respectively.

As we can observe, the substitution of the halide is not reflected in a unidirectional shift of the modes. Thus, the large shift of mode (a) in $\mathrm{FAPbI}_{3}$ at $60 \mathrm{~cm}^{-1}$ as compared to $11 \mathrm{~cm}^{-1}$ in $\mathrm{FAPbBr}_{3}$ may be related to the following fact: the plane in which the rotation takes place is parallel to the crystallographic plane in $\mathrm{FAPbBr}_{3}$ but slightly tilted in the case of $\mathrm{FAPbI}_{3}$ due to the larger free space of the last one. The absence of mode (b) in $\mathrm{FAPbBr}_{3}$ may be explained by the smaller size of the unit cell that makes unfavorable such a notable shift of $\mathrm{FA}^{+}$. Modes (c) and (d) shift from the iodide to bromide in accordance to the halide mass difference, however modes (e) and (f) do not follow this rule. Mode (e) is governed by displacements of hydrogen atoms at the corners of the $\mathrm{FAPbI}_{3}$ unit cell (see Fig. 3e), whereas, in $\mathrm{FAPbBr}_{3}$, these hydrogen atoms remain almost static while $\mathrm{Br}^{-}$ions displace (figure is not presented in this work). We suggest that the magnitude of the displacement of the hydrogen atoms is a consequence of the interaction $\mathrm{H}<->\mathrm{X}$, which is lower for $\mathrm{X}=\mathrm{I}^{-}$than $\mathrm{X}=\mathrm{Br}^{-}$. Therefore, it stipulates a higher frequency of mode (e) for $\mathrm{FAPbI}_{3}$ than for $\mathrm{FAPbBr}_{3}$, whose Raman peaks are present at $429 \mathrm{~cm}^{-1}$ and $368 \mathrm{~cm}^{-1}$, respectively. The higher energy of mode (f) in $\mathrm{FAPbI}_{3}$ is expected to originate from the larger free space provided by the $\mathrm{PbI}_{6}$ octahedra that allow the $\mathrm{FA}^{+}$molecules to vibrate without valuable interactions with the surrounding halides as compared to $\mathrm{FAPbBr}_{3}$.

For Zone III, we compare our calculations of the Raman modes with the specific modes of the isolated $\mathrm{FA}^{+}$ions, disclosed in the theoretical work of Kucharska et al. ${ }^{43}$ In this work, they present 18 internal modes according to the $C_{2 \mathrm{v}}$ symmetry of the $\mathrm{FA}^{+}$molecule, distributed as $\Gamma=7 \mathrm{~A}_{1}+2 \mathrm{~A}_{2}+\mathrm{B}_{1}+$ $3 \mathrm{~B}_{2}$. Our calculations are slightly red-shifted with respect to the isolated cation. This phenomenon is already known for $\mathrm{MAPbX}_{3}$, in which the molecular modes are shifted around $200 \mathrm{~cm}^{-1}$ for $\mathrm{MAPbI}_{3}$ and $350 \mathrm{~cm}^{-1}$ for $\mathrm{MAPbBr}_{3}$. The dependency of the shift magnitude with the halide is due to the formation of hydrogen bonds or other non-covalent interactions, resulting from the difference in elecronegativity. ${ }^{55}$ Our predicted Raman modes for $\mathrm{FAPbI}_{3}$ and $\mathrm{FAPbBr}_{3}$ differ on average $c a .50 \mathrm{~cm}^{-1}$ from the isolated cation. According to Kucharska et al., $\mathrm{FA}^{+}$molecular modes should appear above $521 \mathrm{~cm}^{-1} \cdot{ }^{43}$ Our DFT calculations predict modes already at 507 and $510 \mathrm{~cm}^{-1}$ for $\mathrm{FAPbI}_{3}$ and $\mathrm{FAPbBr}_{3}$, respectively.

\section{Experimental Raman spectra of the FA-based compounds}

Following the discussion of DFT calculations, we focus next on the experimental Raman modes of $\mathrm{FAPbI}_{3}$ and $\mathrm{FAPbBr}_{3}$. In accordance with the previously established order, we discuss the experimental phonon modes in spectral ranges. The Raman spectra of the LHPs containing $\mathrm{FA}^{+}$are shown in Fig. 4. Supporting experimental data for $\mathrm{MAPbI}_{3}$ and $\mathrm{CsPbBr}_{3}$ compounds are provided in the ESI $\dagger$ (Fig. S3).

In Zone I of the experimental spectrum, $\mathrm{FAPbI}_{3}$ and $\mathrm{FAPbBr}_{3}$ present the twist and distortion modes represented by a 
a)

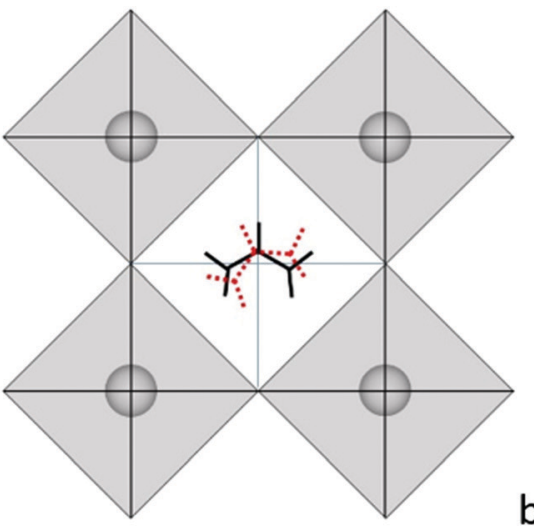

b)

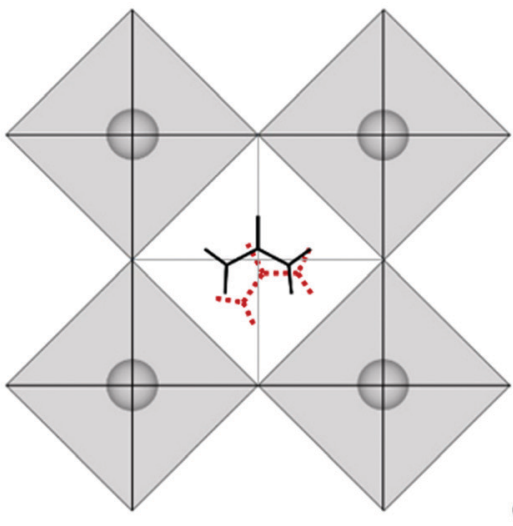

c)
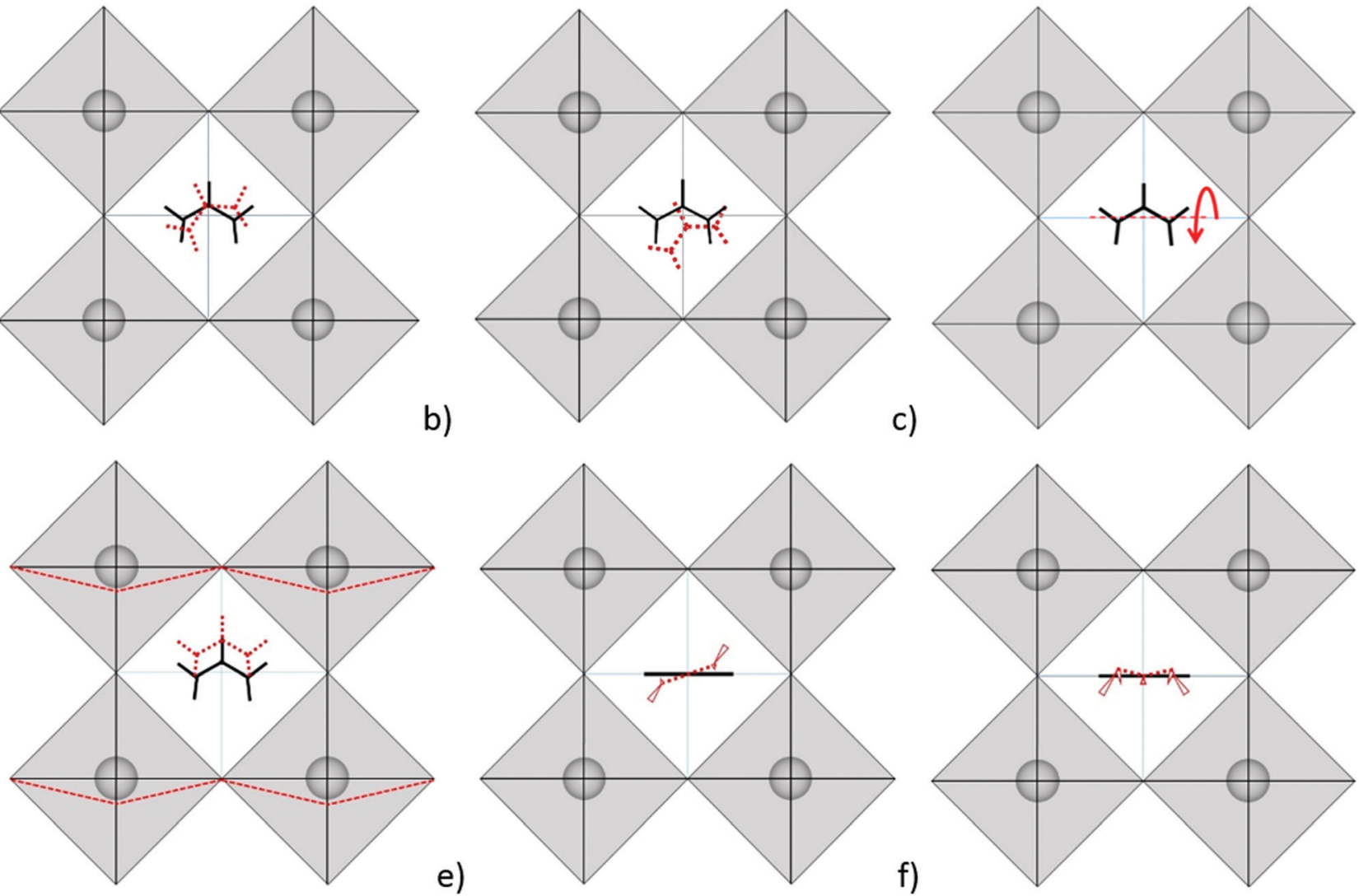

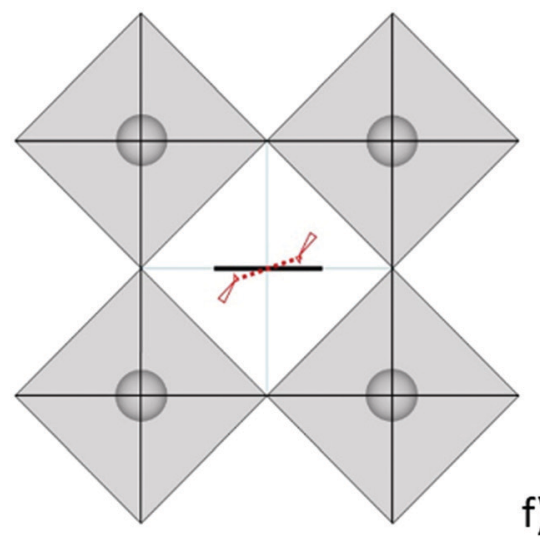

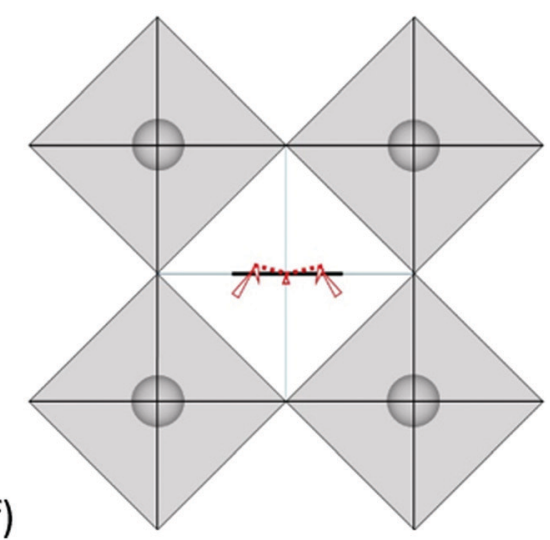

Fig. 3 Schematic representation of the HP modes existing in $\mathrm{FAPbl}_{3}$ according to our DFT calculations: (a) in-plane rotation around the center of mass, (b) in-plane rotation around corner hydrogen, (c) out-of-plane rotation around the $\mathrm{N}-\mathrm{N}$ axis, (d) $\mathrm{FA}^{+}$translation along the $\mathrm{C}-\mathrm{H}$ bond, (e) $\mathrm{H}_{2} \mathrm{~N}-\mathrm{C}-\mathrm{NH}_{2}$ asymmetric out-of-plane bending and (f) $\mathrm{H}_{2} \mathrm{~N}-\mathrm{C}-\mathrm{NH}_{2}$ symmetric out-of-plane bending. Red colors represent changed positions. In cases (e) and (f) the $\mathrm{N}-\mathrm{H}$ and $\mathrm{C}-\mathrm{H}$ bonds project beyond the figure plane that is shown in the perspective view (thicker-closer).

single peak. The absence of splitting peaks indicated a cubic structure for both of them.

Compared to the other LHPs, $\mathrm{FAPbBr}_{3}$ shows broad modes that basically reflect low octahedral activity. This is likely due to the stronger $\mathrm{Pb}-\mathrm{Br}$ bonds than the $\mathrm{Pb}-\mathrm{I}$ bonds and the closerto-unity Goldschmidt Tolerance Factor (GTF) ensuring better fit of $\mathrm{FA}^{+}$to the octahedral cage and therefore a less flexible lattice.

Zone II is analyzed in two sub-zones: a high-coupling range $\left(50-200 \mathrm{~cm}^{-1}\right)$ and a low-coupling one $\left(200-500 \mathrm{~cm}^{-1}\right)$. The spectrum of $\mathrm{FAPbI}_{3}$ in the high-coupling range shows a sharp peak at $114 \mathrm{~cm}^{-1}$ and two broad peaks at $63 \mathrm{~cm}^{-1}$ and $96 \mathrm{~cm}^{-1}$. The spectrum of $\mathrm{FAPbBr}_{3}$ presents broad peaks in this range. In the low-coupling range, the spectrum of $\mathrm{FAPbBr}_{3}$ shows a sharp peak at $308 \mathrm{~cm}^{-1}$ and a broad peak at $470 \mathrm{~cm}^{-1}$.

Assigning the modes of this zone is especially challenging. The experimentally visible modes of $\mathrm{FAPbX}_{3}$ are more frequent than those theoretically predicted in the first sub-zone. Such a difference may be caused by a non-uniform disposition of $\mathrm{FA}^{+}$ cations resulting from the head-to-tail ordering and the neglect of spin-orbit-coupling interactions. ${ }^{1,56,57}$ The head-to-tail ordering was proposed for $\mathrm{FAPbI}_{3}$ as a low energetic arrangement of the molecules in which the $\mathrm{N}-\mathrm{N}$ axis of one $\mathrm{FA}^{+}$is perpendicular to the same axis of the adjacent molecules.
To validate the attribution of the experimental modes of $\mathrm{FAPbX}_{3}$ to the mode description given by the DFT calculations, we compare the coupled modes for $\mathrm{FAPbI}_{3}$ and $\mathrm{MAPbI}_{3}$. It is worth remarking significant differences between $\mathrm{MA}^{+}$and $\mathrm{FA}^{+}$ for further discussion (Fig. S4, ESI + ). In the $\mathrm{FA}^{+}$ion, the positive charge is delocalized between two nitrogen atoms, whereas in $\mathrm{MA}^{+}$it remains only on the $-\mathrm{NH}_{3}{ }^{+}$group. The $\mathrm{N}-\mathrm{C}-\mathrm{N}$ chain becomes more rigid and deflects with an interatomic angle of $125^{\circ}$ due to proton embedding. ${ }^{58}$ According to theoretical calculations, $\mathrm{FA}^{+}$possesses a much lower dipole moment $(0.21 \mathrm{D})$ than $\mathrm{MA}^{+}$ $(2.29 \mathrm{D}){ }^{59}$ The experimentally determined value for $\mathrm{MA}^{+}$is quite low $-0.854 \mathrm{D}^{60}$ resulting in an expected dipole moment of the $\mathrm{FA}^{+}$ cation close to zero. Finally, $\mathrm{FA}^{+}$adopts a planar symmetrical structure.$^{61}$ Such $2 \mathrm{D}$ disposition and weaker polarization enables $\mathrm{FA}^{+}$to vibrate out-of-plane without significant interactions with the surrounding sublattice $\mathrm{PbX}_{6}$. Therefore, the associated Raman modes may present higher frequencies compared to analogous modes of $\mathrm{MAPbX}_{3}$.

Taking into account these differences we can now compare the corresponding coupled modes. In the case of $\mathrm{MAPbI}_{3}$ (see Fig. S2a, ESI $\dagger$ ) these modes derive from the active reorientation of $\mathrm{MA}^{+}$, which mainly rotates in a cone around $\mathrm{N}\left(58,66 \mathrm{~cm}^{-1}\right)$ with a period of $0.3 \mathrm{ps}^{34}$ Other coupled modes represent rotation in a cone around $\mathrm{C}$ and $\mathrm{N}\left(117,133 \mathrm{~cm}^{-1}\right)$, molecular 


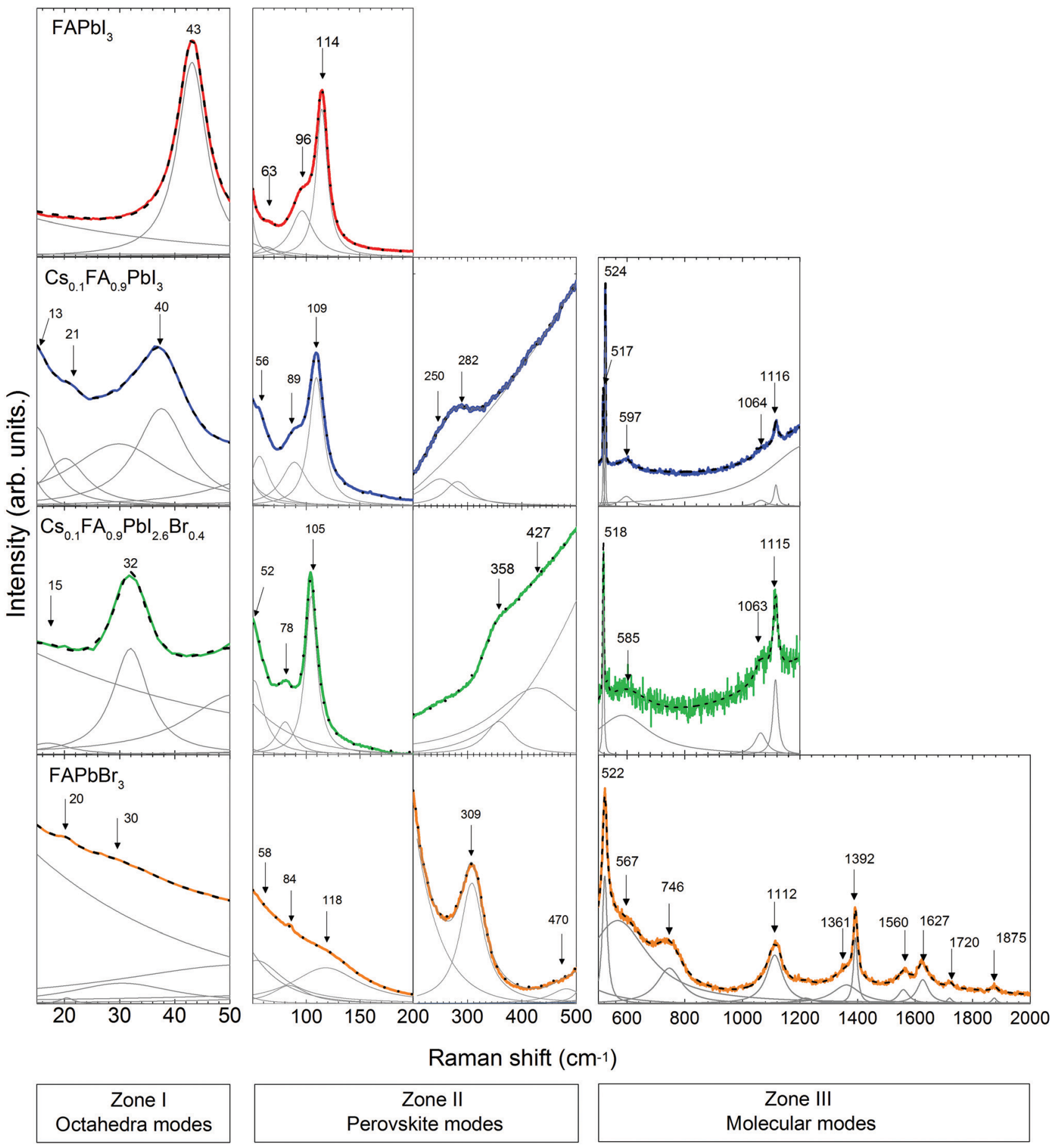

Fig. 4 Raman spectra of FA-based single crystals at RT with an excitation wavelength $\lambda=633 \mathrm{~nm}$, divided into three zones according to the vibration source. Excluded ranges do not exhibit any noticeable Raman lines or are hidden due to strong luminescence. Color lines represent measured spectra, black dashed lines are fits to the spectra and gray lines indicate fitted peaks with Lorentzian line shape.

translations $\left(69,75,81\right.$ and $\left.92 \mathrm{~cm}^{-1}\right)$, rotation around $\mathrm{C}-\mathrm{N}$ $\left(128 \mathrm{~cm}^{-1}\right)$ and $\mathrm{C}-\mathrm{N}$ torsion $\left(315 \mathrm{~cm}^{-1}\right) \cdot{ }^{37}$ The molecular reorientation of $\mathrm{FA}^{+}$is distinctly slower and therefore the corresponding modes shift to lower frequencies. In contrast to that, a dominating movement of the molecules in $\mathrm{FAPbI}_{3}$ is a single roll-over with a time constant of $2 \mathrm{ps}$. The $\mathrm{C}-\mathrm{H}$ bonds remain parallel to the $\{100\}$ planes. $^{34,62}$ Analogous modes of rotation around $\mathrm{C}$ or $\mathrm{N}$ and $\mathrm{C}-\mathrm{N}$ torsion are not expected in $\mathrm{FAPbI}_{3}$ due to the rigid $\mathrm{N}-\mathrm{C}-\mathrm{N}$ frame. Translation modes in $\mathrm{MAPbI}_{3}$ are expected at lower frequencies as compared to $\mathrm{FAPbI}_{3}$. The main reason is the stronger ionic bonding between $\mathrm{MA}^{+}$and $\mathrm{X}^{-}$because $\mathrm{MA}^{+}$has a larger dipole moment and a smaller size than $\mathrm{FA}^{+}$. The large size, rigidity and twist of a dipole moment stipulate slower rotation of $\mathrm{FA}^{+}$around the $\mathrm{N}-\mathrm{N}$ 
Table 1 Classification of Raman peaks of FA-based compounds according to DFT calculations by Kucharska et al. ${ }^{43}$ for isolated FA ${ }^{+}$and DFT calculations by Leguy et al. ${ }^{37}$ for $\mathrm{MAPb}_{3}$. Experimental Raman modes (indicated by ${ }^{*}$ ) are based on the work of $\mathrm{Wang}$ et al. for $\mathrm{FAPbBr}_{3}{ }^{40} \mathrm{Mode}^{\circ}$ frequencies labeled "\#" indicate broad and/or weak shoulder-like peaks without sharp peak-maximum

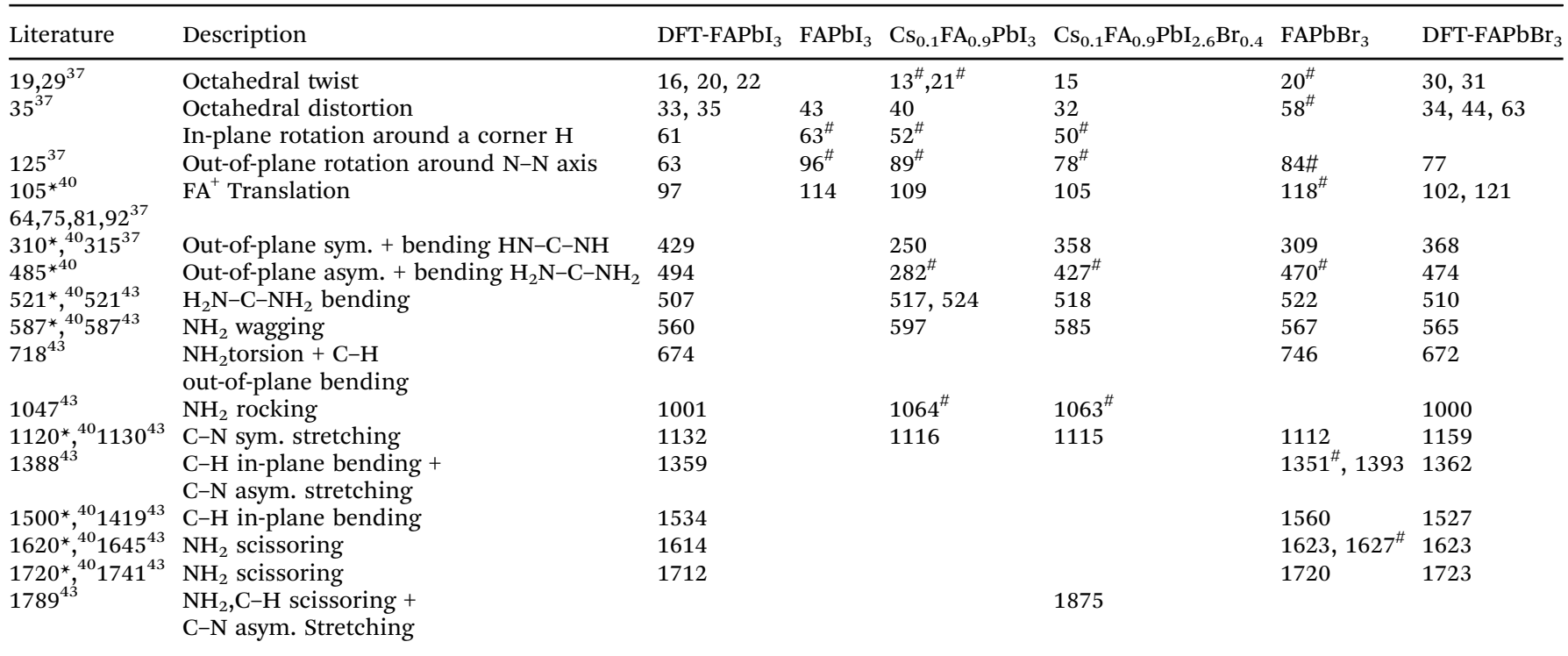

axis in contrast to more frequent $\mathrm{MA}^{+}$rotations around the $\mathrm{C}-\mathrm{N}$ axis. In this way, we attributed the experimental modes of FAPbI $_{3}$ at Zone II and correlated them with the DFT calculated data (see Table 1). Analogously, we attribute the Raman modes for $\mathrm{FAPbBr}_{3}$. As discussed before, the exception is the "in-plane rotation" mode, which is restricted due to the more compact lattice structure.

For the Raman modes of $\mathrm{FAPbBr}_{3}$ at Zone III, we found close agreement between the experimental data and the results from DFT calculations (see Table 1). It is worth noticing that the frequencies of those modes are only slightly shifted with respect to the phonon modes of the isolated $\mathrm{FA}^{+}$, which indicates a weak interaction between the molecules and the $\mathrm{PbBr}_{6}$ octahedra.

To summarize, we have identified the vibrational modes existing in $\mathrm{FAPbI}_{3}$ above $200 \mathrm{~cm}^{-1}$ using DFT calculations. Additionally, we have correlated the DFT results with experimental data obtained for $\mathrm{FAPbBr}_{3}$ single crystals. Table 1 summarizes all modes discussed above and lists their attribution based on the experimental spectra shown in Fig. 2 and 4.

\section{Effect of the partial $\mathrm{Cs}^{+}$and $\mathrm{Br}^{-}$substitutions}

Following the previous discussion, we focus on the effect of partial substitution of $\mathrm{FA}^{+}$by $\mathrm{Cs}^{+}$and $\mathrm{I}^{-}$by $\mathrm{Br}^{-}$on the vibrational behaviour of LHPs and the stabilization of the cubic form. We refer here to XRD and PL measurements (Fig. S5 and S6, ESI $\dagger$ ) of the chosen mixed compounds to support the comparison of the Raman spectra (Fig. 5).

In analogy to the Raman spectra, we compare the XRD patterns of $\mathrm{FAPbI}_{3}$ and the mixed compounds (Fig. S5, ESI $\dagger$ ). Due to the similarity of the patterns, we fit them to the phase structure of $\mathrm{FAPbI}_{3}$ presented in the literature, a cubic $\mathrm{Pm} \overline{3} m$ symmetry. ${ }^{62}$ The (100) diffraction maximum shifts only when $\mathrm{Cs}^{+}$ and $\mathrm{Br}^{-}$are incorporated. The corresponding lattice constants were found to be $6.357 \AA$ for $\mathrm{FAPbI}_{3}$ and $\mathrm{Cs}_{0.1} \mathrm{FA}_{0.9} \mathrm{PbI}_{3}$, and
$6.293 \AA$ for $\mathrm{Cs}_{0.1} \mathrm{FA}_{0.9} \mathrm{PbI}_{2.6} \mathrm{Br}_{0.4}$. The comparison of the reported lattice constants of the pure compounds $\mathrm{FAPbI}_{3}\left(6.3620 \AA^{62}\right)$ and $\mathrm{CsPbI}_{3}\left(6.242 \AA^{63}\right)$ in cubic form suggests a continuity of the phase-structure of $\mathrm{FAPbI}_{3}$ with the incorporation of $\mathrm{Cs}^{+}$. The substitution of $\mathrm{I}^{-}$by $\mathrm{Br}^{-}$results in the expected decrease of the lattice constant due to the smaller size and more electronegative character of the incorporated halide.

For further consideration we assume a homogeneous distribution of $\mathrm{Cs}^{+}$and $\mathrm{Br}^{-}$in the mixed compositions, which is indirectly proven by the PL measurements (Fig. S6, ESI $\dagger$ ) due to the absence of a secondary peak related to separated cesium-rich or bromide-rich zones. We also expect no symmetry change with respect to the cubic $\mathrm{FAPbI}_{3}$.

We discuss first the Raman spectrum of $\mathrm{Cs}_{0.1} \mathrm{FA}_{0.9} \mathrm{PbI}_{3}$. Within the range between 15 and $200 \mathrm{~cm}^{-1}$, it demonstrates a slight red-shift with respect to the spectrum of $\mathrm{FAPbI}_{3}$ : the modes observed at 40 and $109 \mathrm{~cm}^{-1}$ of the mixed compound appear at 43 and $114 \mathrm{~cm}^{-1}$ in $\mathrm{FAPbI}_{3}$, respectively (see Fig. 5). The observed shift of phonon modes to lower frequencies correlates with the previously suggested release of stresses in the $\mathrm{FAPbI}_{3}$ single crystals upon $\mathrm{Cs}^{+}$substitution. The magnitude of this reduction is probably not valuable enough to represent the prolonged stabilization of the cubic structure, which is observed in the degradation of this compound after a few weeks.

In Zone I, the appearance of the twist modes at 13 and $21 \mathrm{~cm}^{-1}$ implies some local distortion due to the incorporation of the $\mathrm{Cs}^{+}$cation. Indeed, it can be expected that the heavier and more electronically spherical $\mathrm{Cs}^{+}$atoms should have notably stronger ionic interaction with the $\mathrm{PbX}_{6}$ framework than the $\mathrm{FA}^{+}$ molecules.

The influence of the incorporation of the $\mathrm{Cs}^{+}$atoms and the effect on the modes of Zone II are analyzed according to the $\mathrm{Cs}^{+}$ atoms displacement from the A-position, considering that they 
$\mathrm{FAPbl}_{3}: \exp$. modes*

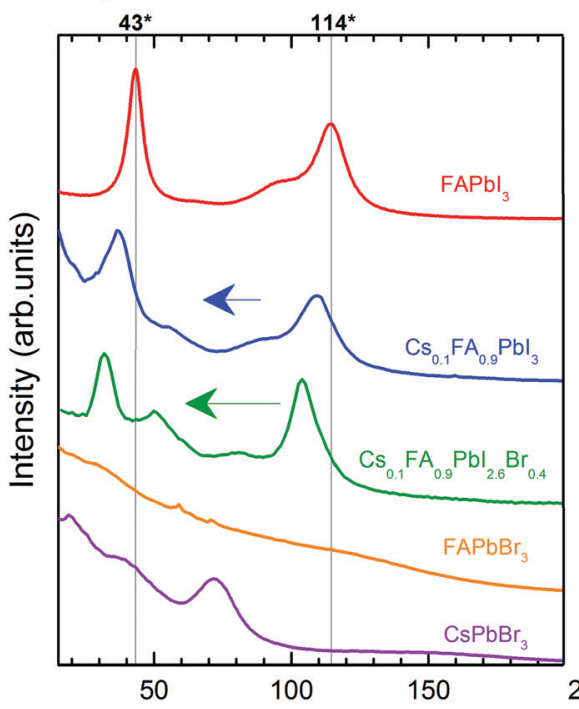

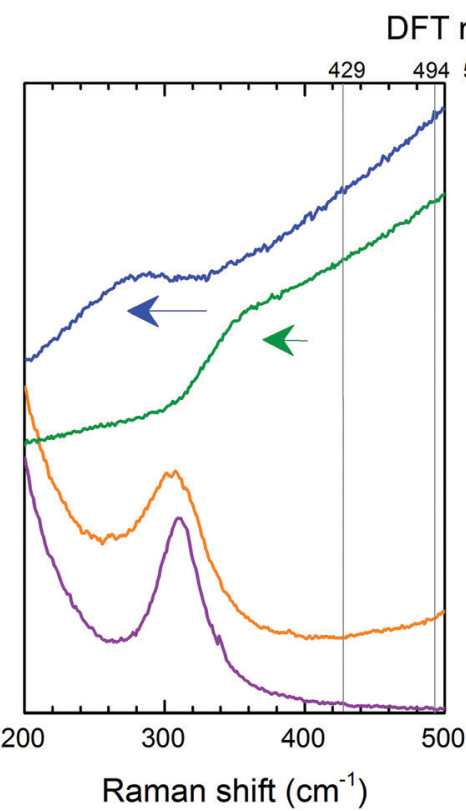

DFT modes

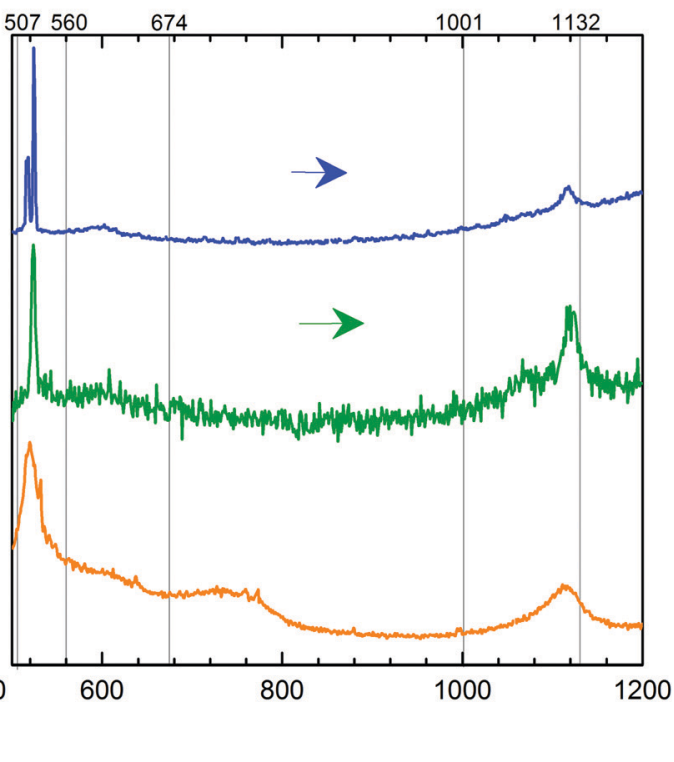

Fig. 5 Raman spectra of $\mathrm{Cs}_{0.1} \mathrm{FA}_{0.9} \mathrm{Pbl}_{3}$ and $\mathrm{Cs}_{0.1} \mathrm{FA}_{0.9} \mathrm{Pbl}_{2.6} \mathrm{Br}_{0.4}$ compared to those of $\mathrm{FAPbl}_{3}, \mathrm{FAPbBr}_{3}$ and $\mathrm{CsPbBr}$. Modes of the same vibrational origin in different LHPs are compared with $\mathrm{FAPbl}_{3}$ and denoted by adjacent arrows. $\mathrm{FAPbl}_{3}$ Raman modes are: octahedral distortion $\left(43 \mathrm{~cm}^{-1}\right)$, translation of the A-cation $\left(114 \mathrm{~cm}^{-1}\right)$, sym. $\left(429 \mathrm{~cm}^{-1}\right)$ and asym. $\left(494 \mathrm{~cm}^{-1}\right)$ bending of $\mathrm{FA}^{+}$(in the case of $\mathrm{CsPbBr}_{3}$, the peak at $309 \mathrm{~cm}^{-1}$ represents a second-order phonon mode), $\mathrm{H}_{2} \mathrm{~N}-\mathrm{C}-\mathrm{NH}_{2}$ bending $\left(507 \mathrm{~cm}^{-1}\right), \mathrm{NH}_{2}$ wagging $\left(560 \mathrm{~cm}^{-1}\right), \mathrm{NH}_{2}$ torsion $+\mathrm{C}-\mathrm{H}$ out-of-plane bending $\left(674 \mathrm{~cm}^{-1}\right), \mathrm{C}-\mathrm{H}$ out-of-plane bending $+\mathrm{NH}$ rocking $\left(1001 \mathrm{~cm}^{-1}\right)$ and $\mathrm{C}-\mathrm{N}$ sym. stretching $\left(1132 \mathrm{~cm}^{-1}\right)$. The spectra were measured at RT using an excitation laser wavelength $\lambda=633 \mathrm{~nm}$.

are contained in a $\mathrm{FAPbI}_{3}$ matrix. For this, we compared the mixed compound $\mathrm{Cs}_{0.1} \mathrm{FA}_{0.9} \mathrm{PbI}_{3}$ with $\mathrm{CsPbBr}_{3}$ in which the atomic trajectories of $\mathrm{Cs}^{+}$are known. ${ }^{42}$ In $\mathrm{CsPbBr}_{3}$, the $\mathrm{Cs}^{+}$ cations have $0.85 \AA$ displacement in a head-to-head motion which is stabilized by a cooperative motion of $\mathrm{Br}^{-}$ions. This means that the octahedral sub-cages that are approached by $\mathrm{Cs}^{+}$ions expand due to Pauli repulsion forces. Therefore, the translation of $\mathrm{Cs}^{+}$in the mixed compound is likely coordinated with the surrounding $\mathrm{FA}^{+}$molecules to reduce the energy of the system during the distortion of the octahedral cages, which results in a shift of the corresponding translation mode from $114 \mathrm{~cm}^{-1}$ in $\mathrm{FAPbI}_{3}$ to $109 \mathrm{~cm}^{-1}$.

In the range from 200 to $500 \mathrm{~cm}^{-1}$, we observe two modes at $250 \mathrm{~cm}^{-1}$ and $282 \mathrm{~cm}^{-1}$. Compared to the DFT calculations of $\mathrm{FAPbI}_{3}$, they may be related to the out-of-plane $\mathrm{FA}^{+}$bending modes which are predicted at 429 and $494 \mathrm{~cm}^{-1}$, respectively (see Table 1). The higher energies of these modes of $\mathrm{FAPbI}_{3}$ basically mean an overestimation of the $\mathrm{FA}^{+}-\mathrm{I}^{-}$interaction in our theoretical model. This may originate from deviations from the assumed $P m \overline{3} m$ space group and/or considerable contributions of $\mathrm{Cs}^{+}$to this interaction. $\mathrm{CsPbBr}_{3}$ reveals a second-order-phonon mode at $312 \mathrm{~cm}^{-1}$ related to $\mathrm{Cs}^{+}$translations, which may influence the $\mathrm{FA}^{+}$-bending via variations of the internal electric field. The same modes appear in $\mathrm{FAPbBr}_{3}$ at 309 and $470 \mathrm{~cm}^{-1}$ respectively.

The Raman spectrum of $\mathrm{Cs}_{0.1} \mathrm{FA}_{0.9} \mathrm{PbI}_{3}$ in Zone III presents peaks at frequencies in good agreement with the predicted ones by the DFT calculations of the molecular modes of $\mathrm{FAPbI}_{3}$. One noticeable difference between them is the splitting of the mode around $520 \mathrm{~cm}^{-1}$ present only for the former case. This may be related to the previously discussed lowering of symmetry.
In this case, the frequency of the mode "molecular bending" depends on the position of the molecule inside the cage. This distortion in the structure was previously discussed from the presence of an additional peak for the "octahedral twist" mode.

To summarize, the effect of $\mathrm{Cs}^{+}$substitution in the Raman spectrum of $\mathrm{FAPbI}_{3}$ can be appreciated in a red-shift of the medium-frequency spectrum $\left(<500 \mathrm{~cm}^{-1}\right)$ due to the release of stresses of the $\mathrm{Pb}-\mathrm{I}$ bonds and the coordination of the translations of $\mathrm{Cs}^{+}$and $\mathrm{FA}^{+}$.

The Raman spectrum of $\mathrm{Cs}_{0.1} \mathrm{FA}_{0.9} \mathrm{PbI}_{2.6} \mathrm{Br}_{0.4}$ shows a red shift compared to the spectrum of $\mathrm{Cs}_{0.1} \mathrm{FA}_{0.9} \mathrm{PbI}_{3}$ for low frequencies $\left(<200 \mathrm{~cm}^{-1}\right)$. The octahedral distortion peak shifts from 40 to $32 \mathrm{~cm}^{-1}$ and the translation one from 109 to $105 \mathrm{~cm}^{-1}$. This is counterintuitive as the lighter $\mathrm{Br}$ ions are expected to cause a shift to higher phonon frequencies. We observe a similar unexplained red shift effect in $\mathrm{CsPbBr}_{3}$ as compared to $\mathrm{CsPbI}_{3}$. For these materials, the most prominent peaks that we can ascribe to the Raman modes "distortion of the octahedra" and "translation of $\mathrm{Cs}^{+,}$, are present at 55 and $108 \mathrm{~cm}^{-1}$ in $\mathrm{CsPbI}_{3}{ }^{64}$ and at 40 and $73 \mathrm{~cm}^{-1}$ in $\mathrm{CsPbBr}_{3}$ (see Fig. S3, ESI $\dagger$ ), respectively. The structure of $\mathrm{CsPbr}_{3}$ is more compact compared to $\mathrm{CsPbI}_{3}$, as suggested by a GTF closer to 1 ( 0.974 vs. 0.836 , respectively). Therefore, we suggest an effect of the strength release of the $\mathrm{Pb}-\mathrm{X}$ bonds as in both cases a red shift is accompanied by an increase of the GTF (see Table S2, ESI $\dagger$ ).

In Zone I, the disappearance of the second peak of the "octahedral twist" mode at $21 \mathrm{~cm}^{-1}$ of $\mathrm{Cs}_{0.1} \mathrm{FA}_{0.9} \mathrm{PbI}_{3}$ suggests that the emergence of additional stresses in the $\mathrm{PbX}_{6}$ structure caused by the incorporation of $\mathrm{Cs}^{+}$somehow counteracts the distortion introduced by $\mathrm{Br}^{-1}$. 
The peaks of the high-coupling range of Zone II $\left(50-200 \mathrm{~cm}^{-1}\right)$ are red-shifted as previously discussed. In the low-coupling range (200-500 $\mathrm{cm}^{-1}$ ), the modes at 250 and $282 \mathrm{~cm}^{-1}$ expectedly shift to higher energies: 358 and $427 \mathrm{~cm}^{-1}$ respectively. Similar Raman mode frequencies of 429 and $494 \mathrm{~cm}^{-1}$ are found for pure $\mathrm{FAPbI}_{3}$. This can be understood considering that the modes in this frequency range are influenced by the internal electric field which determines the strength of the coupling. A combination of the less frequent translation of $\mathrm{Cs}^{+}$atoms with the stronger $\mathrm{PbX}_{6}$ octahedral bonds results in the weakening of the interaction between $\mathrm{FA}^{+}$ molecules and the $\mathrm{PbX}_{6}$ octahedra.

The Raman modes of Zone III of $\mathrm{Cs}_{0.1} \mathrm{FA}_{0.9} \mathrm{PbI}_{2.6} \mathrm{Br}_{0.4}$ have quite similar frequencies to the modes of $\mathrm{Cs}_{0.1} \mathrm{FA}_{0.9} \mathrm{PbI}_{3}$. The splitting of the mode around $520 \mathrm{~cm}^{-1}$ is absent in the former case, which supports the lowering of the distortion created by the incorporation of $\mathrm{Cs}^{+}$. Compared to $\mathrm{FAPbBr}_{3}$, the mixed compounds do not present a peak at $740 \mathrm{~cm}^{-1}$, related to the combined vibration of $\mathrm{NH}_{2}$ torsion and $\mathrm{C}-\mathrm{H}$ out plane bending and predicted for $\mathrm{FAPbI}_{3}$ at $674 \mathrm{~cm}^{-1}$. Instead, they present a broad peak around $1064 \mathrm{~cm}^{-1}$ assigned to $\mathrm{NH}_{2}$ rocking. The activation of different modes is likely a consequence of the lattice size.

In conclusion, the incorporation of $\mathrm{Br}^{-}$affects the dynamics of $\mathrm{Cs}^{+}$, hindering the frequency of the atomic displacement due to enhanced lattice compactness. This is expressed in the red-shift of the low-frequency range $\left(<200 \mathrm{~cm}^{-1}\right)$. A blue shift of the lowcoupled modes (from 200 to $500 \mathrm{~cm}^{-1}$ ) of $\mathrm{Cs}_{0.1} \mathrm{FA}_{0.9} \mathrm{PbI}_{2.6} \mathrm{Br}_{0.4}$ towards the frequencies of the Raman modes of $\mathrm{FAPbI}_{3}$ indicates softening in the interaction of the $\mathrm{FA}^{+}$molecules and the octahedra. Therefore, the structure is stabilized in a cubic form due to the reduction of the stresses in the $\mathrm{Pb}-\mathrm{X}$ bonds, resulting in a more compact crystalline lattice. In this case, the frequency of cooperative translation in the A-site is hindered by the surrounding $\mathrm{Br}^{-}$atoms.

\section{Conclusions}

We have reported the vibrational properties of formamidinium (FA)-based LHPs investigated by micro-Raman spectroscopy. The experimental spectra were presented for the first time for the cubic forms of $\mathrm{FAPbI}_{3}, \mathrm{Cs}_{0.1} \mathrm{FA}_{0.9} \mathrm{PbI}_{3}$ and $\mathrm{Cs}_{0.1} \mathrm{FA}_{0.9} \mathrm{PbI}_{2.6} \mathrm{Br}_{0.4}$ hybrid perovskites. Theoretical Raman spectra were obtained for $\mathrm{FAPbBr}_{3}$ and $\mathrm{FAPbI}_{3}$ using DFT calculations to support the identification of the experimental Raman modes.

Low frequency Raman modes of LHPs $\left(<50 \mathrm{~cm}^{-1}\right.$ for I-based and $<65 \mathrm{~cm}^{-1}$ for Br-based) can be assigned to the vibrational modes of the $O_{\mathrm{h}}$ symmetry, twist and distortion of the octahedra. Medium frequency Raman modes (from 50 to $500 \mathrm{~cm}^{-1}$ ) of FA-containing LHPs are derived for molecular reorganization and the consequent octahedral response, which are in-plane and out-of-plane rotations, and symmetric and asymmetric out-of-plane bending. The closeness of energies of $\mathrm{FA}^{+}$modes above $500 \mathrm{~cm}^{-1}$ for $\mathrm{FAPbBr}_{3}$ and the isolated $\mathrm{FA}^{+}$ ions denotes a low interaction between the molecules and the $\mathrm{PbBr}_{6}$ octahedra. This is presumed to result from the neglectable dipole moment of the $\mathrm{FA}^{+}$ions.
The improved stability of $\mathrm{FAPbI}_{3}$ due to the incorporation of $\mathrm{Cs}^{+}$and $\mathrm{Br}^{-}$is the result of the combined effect of both components. It is explained by the release of stresses of the $\mathrm{Pb}-\mathrm{X}$ bonds, which is a consequence of a more compact lattice and a less frequent displacement of the $\mathrm{FA}^{+}$ions resulting from the coupling with the $\mathrm{Cs}^{+}$atoms. This is expressed in the Raman spectrum as a red-shift of the octahedra related modes $\left(<500 \mathrm{~cm}^{-1}\right)$.

\section{Conflicts of interest}

There are no conflicts to declare.

\section{Acknowledgements}

The authors gratefully acknowledge the financial support provided by the Scholarship Becas Chile-DAAD 2017/91645541 and the German Research Foundation within the Collaborative Research Center 787 (SFB 787), and the Paderborn Center for Parallel Computing $\left(\mathrm{PC}^{2}\right)$ for computing time on OCuLUS and FPGA-based supercomputer NOCTUA. This work was also supported by the German Federal Ministry for Economic Affairs and Energy (BMWi) under contract number 0324095H (speedCIGS).

\section{References}

1 C. C. Stoumpos, C. D. Malliakas and M. G. Kanatzidis, Inorg. Chem., 2013, 52, 9019-9038.

2 J. Chen, S. Zhou, S. Jin, H. Li and T. Zhai, J. Mater. Chem. C, 2016, 4, 11-27.

3 D. P. McMeekin, G. Sadoughi, W. Rehman, G. E. Eperon, M. Saliba, M. T. Hoerantner, A. Haghighirad, N. Sakai, L. Korte and B. Rech, et al., Science, 2016, 351, 151-155.

4 J. H. Noh, S. H. Im, J. H. Heo, T. N. Mandal and S. I. Seok, Nano Lett., 2013, 13, 1764-1769.

5 Z. Yang, C.-C. Chueh, P.-W. Liang, M. Crump, F. Lin, Z. Zhu and A. K.-Y. Jen, Nano Energy, 2016, 22, 328-337.

6 G. E. Eperon, S. D. Stranks, C. Menelaou, M. B. Johnston, L. M. Herz and H. J. Snaith, Energy Environ. Sci., 2014, 7, 982-988.

7 C. M. Sutter-Fella, Y. Li, M. Amani, J. W. Ager III, F. M. Toma, E. Yablonovitch, I. D. Sharp and A. Javey, Nano Lett., 2015, 16, 800-806.

8 H. J. Snaith, J. Phys. Chem. Lett., 2013, 4, 3623-3630.

9 X.-Y. Zhu and V. Podzorov, Charge carriers in hybrid organicinorganic lead halide perovskites might be protected as large polarons, 2015.

10 K. Miyata, D. Meggiolaro, M. T. Trinh, P. P. Joshi, E. Mosconi, S. C. Jones, F. De Angelis and X.-Y. Zhu, Sci. Adv., 2017, 3, e1701217.

11 X. Zhao, J. D. A. Ng, R. H. Friend and Z.-K. Tan, ACS Photonics, 2018, 5, 3866-3875.

12 C. Yi, J. Luo, S. Meloni, A. Boziki, N. Ashari-Astani, C. Graetzel, S. M. Zakeeruddin, U. Röthlisberger and M. Graetzel, Energy Environ. Sci., 2016, 9, 656-662. 
13 A. Kojima, K. Teshima, Y. Shirai and T. Miyasaka, J. Am. Chem. Soc., 2009, 131, 6050-6051.

14 Y. Wang, Y. Zhang, Y. Lu, W. Xu, H. Mu, C. Chen, H. Qiao, J. Song, S. Li and B. Sun, et al., Adv. Opt. Mater., 2015, 3, 1389-1396.

15 F. Li, C. Ma, H. Wang, W. Hu, W. Yu, A. D. Sheikh and T. Wu, Nat. Commun., 2015, 6, 8238.

16 X. Wang, H. Zhou, S. Yuan, W. Zheng, Y. Jiang, X. Zhuang, H. Liu, Q. Zhang, X. Zhu and X. Wang, et al., Nano Res., 2017, 10, 3385-3395.

17 H. Zhu, Y. Fu, F. Meng, X. Wu, Z. Gong, Q. Ding, M. V. Gustafsson, M. T. Trinh, S. Jin and X. Zhu, Nat. Mater., 2015, 14, 636.

18 Q. Dong, Y. Fang, Y. Shao, P. Mulligan, J. Qiu, L. Cao and J. Huang, Science, 2015, 347, 967-970.

19 S. Yakunin, D. N. Dirin, Y. Shynkarenko, V. Morad, I. Cherniukh, O. Nazarenko, D. Kreil, T. Nauser and M. V. Kovalenko, Nat. Photonics, 2016, 10, 585.

20 O. Nazarenko, S. Yakunin, V. Morad, I. Cherniukh and M. V. Kovalenko, NPG Asia Mater., 2017, 9, e373.

21 H. Wei, Y. Fang, P. Mulligan, W. Chuirazzi, H.-H. Fang, C. Wang, B. R. Ecker, Y. Gao, M. A. Loi and L. Cao, et al., Nat. Photonics, 2016, 10, 333.

22 Y. Zhao, H. Tan, H. Yuan, Z. Yang, J. Z. Fan, J. Kim, O. Voznyy, X. Gong, L. N. Quan and C. S. Tan, et al., Nat. Commun., 2018, 9, 1607.

23 S. Pang, H. Hu, J. Zhang, S. Lv, Y. Yu, F. Wei, T. Qin, H. Xu, Z. Liu and G. Cui, Chem. Mater., 2014, 26, 1485-1491.

24 N. Pellet, P. Gao, G. Gregori, T.-Y. Yang, M. K. Nazeeruddin, J. Maier and M. Graetzel, Angew. Chem., 2014, 126, 3215-3221.

25 Q. Han, S.-H. Bae, P. Sun, Y.-T. Hsieh, Y. Yang, Y. S. Rim, H. Zhao, Q. Chen, W. Shi and G. Li, et al., Adv. Mater., 2016, 28, 2253-2258.

26 M. I. Saidaminov, A. L. Abdelhady, G. Maculan and O. M. Bakr, Chem. Commun., 2015, 51, 17658-17661.

27 Z. Li, M. Yang, J.-S. Park, S.-H. Wei, J. J. Berry and K. Zhu, Chem. Mater., 2015, 28, 284-292.

28 D. Forgács, D. Pérez-del Rey, J. Ávila, C. Momblona, L. GilEscrig, B. Daenekamp, M. Sessolo and H. J. Bolink, J. Mater. Chem. A, 2017, 5, 3203-3207.

29 I. Lignos, V. Morad, Y. Shynkarenko, C. Bernasconi, R. M. Maceiczyk, L. Protesescu, F. Bertolotti, S. Kumar, S. T. Ochsenbein and N. Masciocchi, et al., ACS Nano, 2018, 12, 5504-5517.

30 M. A. Becker, R. Vaxenburg, G. Nedelcu, P. C. Sercel, A. Shabaev, M. J. Mehl, J. G. Michopoulos, S. G. Lambrakos, N. Bernstein and J. L. Lyons, et al., Nature, 2018, 553, 189.

31 V. V. Belykh, D. R. Yakovlev, M. M. Glazov, P. S. Grigoryev, M. Hussain, J. Rautert, D. N. Dirin, M. V. Kovalenko and M. Bayer, Nat. Commun., 2019, 10, 673.

32 M. Puppin, S. Polishchuk, N. Colonna, A. Crepaldi, D. Dirin, O. Nazarenko, R. De Gennaro, G. Gatti, S. Roth and T. Barillot, et al., 2019, arXiv preprint arXiv:1909.00248.

33 E. T. Hoke, D. J. Slotcavage, E. R. Dohner, A. R. Bowring, H. I. Karunadasa and M. D. McGehee, Chem. Sci., 2015, 6, 613-617.

34 A. A. Bakulin, O. Selig, H. J. Bakker, Y. L. Rezus, C. Mueller, T. Glaser, R. Lovrincic, Z. Sun, Z. Chen and A. Walsh, et al., J. Phys. Chem. Lett., 2015, 6, 3663-3669.
35 S. Brittman, G. W. P. Adhyaksa and E. C. Garnett, MRS Commun., 2015, 5, 7-26.

36 Y. Guo, O. Yaffe, D. W. Paley, A. N. Beecher, T. D. Hull, G. Szpak, J. S. Owen, L. E. Brus and M. A. Pimenta, Phys. Rev. Mater., 2017, 1, 042401.

37 A. M. Leguy, A. R. Goñi, J. M. Frost, J. Skelton, F. Brivio, X. Rodrguez-Martnez, O. J. Weber, A. Pallipurath, M. I. Alonso and M. Campoy-Quiles, et al., Phys. Chem. Chem. Phys., 2016, 18, 27051-27066.

38 R. G. Niemann, A. G. Kontos, D. Palles, E. I. Kamitsos, A. Kaltzoglou, F. Brivio, P. Falaras and P. J. Cameron, J. Phys. Chem. C, 2016, 120, 2509-2519.

39 A. Y. Lee, D. Y. Park and M. S. Jeong, J. Alloys Compd., 2018, 738, 239-245.

40 L. Wang, K. Wang and B. Zou, J. Phys. Chem. Lett., 2016, 7, 2556-2562.

41 J.-H. Cha, J. H. Han, W. Yin, C. Park, Y. Park, T. K. Ahn, J. H. Cho and D.-Y. Jung, J. Phys. Chem. Lett., 2017, 8, 565-570.

42 O. Yaffe, Y. Guo, L. Z. Tan, D. A. Egger, T. Hull, C. C. Stoumpos, F. Zheng, T. F. Heinz, L. Kronik and M. G. Kanatzidis, et al., Phys. Rev. Lett., 2017, 118, 136001.

43 E. Kucharska, J. Hanuza, A. Ciupa, M. Maczka and L. Macalik, Vib. Spectrosc., 2014, 75, 45-50.

44 M. Carignano, Y. Saeed, S. A. Aravindh, I. S. Roqan, J. Even and C. Katan, Phys. Chem. Chem. Phys., 2016, 18, 27109-27118.

45 M. A. Carignano, S. A. Aravindh, I. S. Roqan, J. Even and C. Katan, J. Phys. Chem. C, 2017, 121, 20729-20738.

46 R. O. Jones, Rev. Mod. Phys., 2015, 87, 897-923.

47 D. N. Dirin, I. Cherniukh, S. Yakunin, Y. Shynkarenko and M. V. Kovalenko, Chem. Mater., 2016, 28, 8470-8474.

48 M. Ledinsky, P. Loeper, B. Niesen, J. Holovsky, S.-J. Moon, J.-H. Yum, S. De Wolf, A. Fejfar and C. Ballif, J. Phys. Chem. Lett., 2015, 6, 401-406.

49 P. E. Bloechl, Phys. Rev. B: Condens. Matter Mater. Phys., 1994, 50, 17953.

50 G. Kresse and J. Furthmueller, Comput. Mater. Sci. 1996, 6, 15-50.

51 G. Kresse and J. Furthmueller, Phys. Rev. B: Condens. Matter Mater. Phys., 1996, 54, 11169.

52 J. Klimeš, D. R. Bowler and A. Michaelides, Phys. Rev. B: Condens. Matter Mater. Phys., 2011, 83, 195131.

53 A. Fonari and S. Stauffer, VASP Raman, 2013, https://github. com/raman-sc/VASP/.

54 J. Weidlein, U. Mueller and K. Dehnicke, Schwingungsspektroskopie: eine Einfuehrung, Thieme, 1982.

55 T. Glaser, C. Mueller, M. Sendner, C. Krekeler, O. E. Semonin, T. D. Hull, O. Yaffe, J. S. Owen, W. Kowalsky and A. Pucci, et al., J. Phys. Chem. Lett., 2015, 6, 2913-2918.

56 A. Amat, E. Mosconi, E. Ronca, C. Quarti, P. Umari, M. K. Nazeeruddin, M. Graetzel and F. De Angelis, Nano Lett., 2014, 14, 3608-3616.

57 C. Quarti, G. Grancini, E. Mosconi, P. Bruno, J. M. Ball, M. M. Lee, H. J. Snaith, A. Petrozza and F. De Angelis, J. Phys. Chem. Lett., 2013, 5, 279-284.

58 J. Oszczapowicz, C. U. Regelmann and G. Haefelinger, J. Chem. Soc., Perkin Trans. 2, 1990, 1551-1557. 
59 J. M. Frost, K. T. Butler, F. Brivio, C. H. Hendon, M. Van Schilfgaarde and A. Walsh, Nano Lett., 2014, 14, 2584-2590.

60 A. Poglitsch and D. Weber, J. Chem. Phys., 1987, 87, 6373-6378.

61 A. A. Petrov, E. A. Goodilin, A. B. Tarasov, V. A. Lazarenko, P. V. Dorovatovskii and V. N. Khrustalev, Acta Crystallogr., Sect. E: Crystallogr. Commun., 2017, 73, 569-572.
62 M. T. Weller, O. J. Weber, J. M. Frost and A. Walsh, J. Phys. Chem. Lett., 2015, 6, 3209-3212.

63 M. Ahmad, G. Rehman, L. Ali, M. Shafiq, R. Iqbal, R. Ahmad, T. Khan, S. Jalali-Asadabadi, M. Maqbool and I. Ahmad, J. Alloys Compd., 2017, 705, 828-839.

64 G. Yuan, S. Qin, X. Wu, H. Ding and A. Lu, Phase Transitions, 2018, 91, 38-47. 